\title{
Large-Aperture, High-Damage-Threshold Optics for Beamlet
}

\author{
J. H. Campbell \\ L. J. Atherton \\ J. J. DeYoreo \\ M. R. Kozlowski \\ R. T. Maney \\ R. C. Montesanti \\ L. M. Sheehan \\ C. E. Barker
}

February 23, 1995

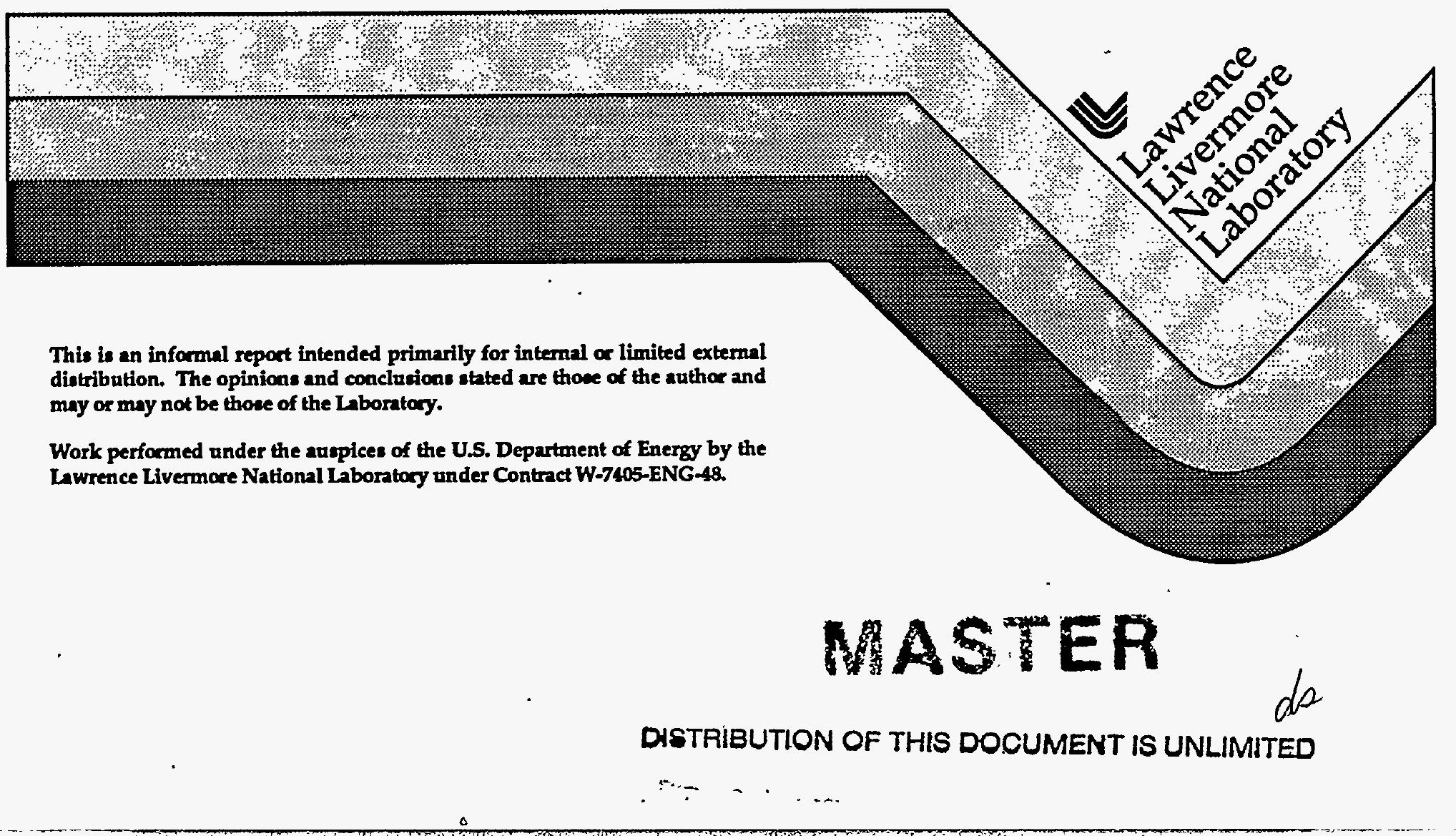




\section{DISCLAIMER}

This document was prepared as an account of work sponsored by an agency of the United States Government. Neither the United States Government nor the University of California nor any of their employees, makes any warranty, express or implied, or assumes any legal liability or responsibility for the accuracy, completeness, or usefulness of any information, apparatus, product, or process disclosed, or represents that its use would not infringe privately owned rights. Reference herein to any specific commercial product, process, or service by trade name, trademark, manufacturer, or otherwise, does not necessarily constitute or imply its endorsement, recommendation, or favoring by the United States Government or the University of California. The views and opinions of authors expressed herein do not necessarily state or reflect those of the United States Government or the University of California, and shall not be used for advertising or product endorsement purposes.

This report has been reproduced directly from the best available copy.

Available to DOE and DOE contractors from the

Office of Scientific and Technical Information

P.O. Box 62, Oak Ridge, TN 37831

Prices available from (615) 576-8401, FTS 626-8401

Available to the public from the

National Technical Information Service

U.S. Department of Commerce

5285 Port Royal Rd.,

Springfield, VA 22161

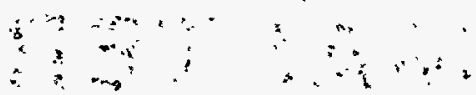




\section{DISCLAIMER}

Portions of this document may be illegible in electronic image products. Images are produced from the best available original document. 


\title{
Large-Aperture, High-Damage-Threshold Optics for Beamlet
}

\author{
J. H. Campbell
}

L. J. Atherton

J. J. DeYoreo

M. R. Kozlowski

R. T. Maney

R. C. Montesanti

L. M. Sheehan

C. E. Barker

\section{Introduction}

Beamlet serves as a test bed for the proposed NIF laser design and components. Therefore, its optics are similar in size and quality to those proposed for the NIF. In general, the optics in the main laser cavity and transport section of Beamlet are larger and have higher damage thresholds than the optics manufactured for any of our previous laser systems. In addition, the quality of the Beamlet optical materials is higher, leading to better wavefront quality, higher optical transmission, and lower-intensity modulation of the output laser beam than, for example, that typically achieved on Nova. In this article, we discuss the properties and characteristics of the large-aperture optics used on Beamlet.

The damage threshold is perhaps the most critical property of the optical materials, because the cost of the laser system is driven largely by the amount of 
laser energy that can be delivered in a given aperture size. The higher the transmitted energy density (fluence), the fewer the number of laser beams needed to meet the output energy requirement and, therefore, the lower the overall system cost. Consequently, Beamlet (and NIF) are designed to operate near the damage threshold limit for the optical materials.

Table 1 summarizes the damage threshold requirements at 1.0 and $0.35 \mu \mathrm{m}$ for the large optics on Beamlet for a nominal operating pulse length of 3 ns and lists the measured damage thresholds for comparison. Note that the measured thresholds represent the absolute maximum operating laser fluence possible for that specific optic. To provide a safety margin for our designed operating limit, we multiply the measured thresholds by a "de-rating" factor that accounts for measurement uncertainties. The product of the measured damage threshold times the de-rating factor is called the "safe operating limit" and represents the fluence limit for that specific optic. Beamlet is designed to never exceed the safe operating limits.

Figure 1 compares the peak designed laser fluence at key optical materials on Beamlet with the safe operating threshold. These peak fluences are reached during the final pass through the laser and are based on model calculations. Note that the peak fluence determines the damage limit of the laser, whereas the average fluence determines the energy output. Therefore on the Beamlet, we have worked hard to keep the peak-to-mean intensity variation within the laser pulse as low as possible to maximize the energy out and to minimize the risk of optical damage. Because laser optical materials do not all have the same damage thresholds, one or two materials generally limit the performance of the system. In the case of Beamlet, the optical material at most risk is the $\mathrm{HfO}_{2} / \mathrm{SiO}_{2}$ multilayer thin film polarizer (at $1 \omega$ ) and the deuterated potassium dihydrogen phosphate $\left(K D^{*} P\right)$ tripling crystal (at $\left.3 \omega\right)$.

\section{Optical Materials}


The optical materials on Beamlet can be divided into four main types: laser glass, potassium dihydrogen phosphate (KDP)/KD*P, dielectric coatings, and lenses and diagnostic beam splitters. This section briefly describes each of these materials and their key properties.

\section{Laser Glass}

The energy storage medium for the Beamlet flash-lamp-pumped amplifiers is a commercial phosphate laser glass (composition LG-750) manufactured by Schott Glass Technologies Inc. It has an $\mathrm{Nd}^{3+}$ doping concentration of $3.4 \times 10^{20} / \mathrm{cm}^{3}$ and consists of a meta-phosphate glass composition. Although the details of the composition are proprietary, it contains the major oxides $\mathrm{P}_{2} \mathrm{O}_{5}, \mathrm{Al}_{2} \mathrm{O}_{3}, \mathrm{~K} 2 \mathrm{O}, \mathrm{BaO}$, $\mathrm{Nd}_{2} \mathrm{O}_{3}$, and a number of other miscellaneous components.

For Beamlet (and NIF) the laser glass is in the form of large rectangular plates $78.8 \times 44.8 \times 4 \mathrm{~cm}^{3}$ (Fig. 2). The volume of these glass plates or "slabs" is about $14 \mathrm{~L}$. For comparison, the largest pieces of Nova laser glass are elliptically shaped disks and have a volume of about $7 \mathrm{~L}$. Thus, the size and shape of Beamlet's slabs required a significant advancement in the prior laser glass manufacturing process. A total of 20 slabs were manufactured for the Beamlet laser-16 are installed on the system, and 4 are reserved as spares.

The size of the Beamlet laser slabs is driven by four main factors: (1) The maximum beam size, which is $35 \mathrm{~cm}$ for Beamlet. In addition, the laser slab is mounted in the amplifier cavity at Brewster's angle, requiring that the slab be lengthened to account for both the angle and the refractive "walk-off" of the beam as it travels through the glass. (2) The vignetting effect, allowing for the beam to propagate back and forth four times through the main laser cavity slightly off-axis to pass through the four different pinholes. (See "System Description and Initial Performance Results for Beamlet," p. _.) The contribution of the vignette to the 
slab size is dependent on the length of the cavity amplifier section and the pinhole spacing. (3) The alignment allowance which, within the main laser cavity, is set at $2 \%$ of the maximum beam size. (4) The stand-off distance from the edge cladding, required to avoid wavefront distortion of the beam caused by amplified spontaneous emission (ASE) heating the cladding. When the cladding is heated, it expands and distorts the region near the edge of the slab. Based on experiments, ${ }^{1}$ the stand-off distance from the edge cladding bond line needs to be at least $t / 2$, where $t$ is the slab thickness. Since Beamlet slabs are $4 \mathrm{~cm}$ thick, the minimum stand-off distance is $2 \mathrm{~cm}$ around the border of the entire slab.

The laser slabs are clad with $\mathrm{Cu}$-doped phosphate glass having an absorption coefficient at $1.05 \mu \mathrm{m}$ of $0.28 / \mathrm{mm}$. The base composition of the cladding glass is the same as LG-750 (without the $\mathrm{Nd}^{3+}$ ) and is bonded to the laser slabs using an epoxy adhesive specially formulated to match the index of the laser glass. Details for the cladding process are described elsewhere. ${ }^{2}$ The laser slabs were clad and finished by Zygo Corporation and Eastman Kodak Company.

Laser glasses are specially formulated to give the desired laser, optical, thermal-mechanical, and physical-chemical properties needed for a specific application. Most of these properties are controlled by the base composition of the glass. However, some critical properties are also impacted by the manufacturing process. These include the optical absorption at $1054 \mathrm{~nm}$, optical homogeneity, $\mathrm{Nd}^{3+}$ fluorescence lifetime, and the Pt inclusion content. Because of Beamlet's larger slabs, we were concerned whether these critical properties could be maintained throughout the process. Figure 3(a) shows the variation in optical absorption at 1054 $\mathrm{nm}$ for all the slabs produced. Optical absorption arises from either impurities in the raw materials and/or contaminants that enter during the processing (e.g., contaminants added by dissolution of the melter refractory walls). 3 The absorption offsets the laser gain of the material, thereby requiring either more amplifiers or 
harder pumping. The data in Fig. 3(a) show that the Beamlet slabs have very low absorption loss and meet the necessary absorption specification. In fact, about $30 \%$ of the absorption loss (i.e., $4.5 \times 10^{-4} \mathrm{~cm}^{-1}$ ) is due to absorption by the thermal population of $\mathrm{Nd}^{3+}$ in the lower laser level $\left({ }^{4} \mathrm{I}_{11 / 2}\right)$.

The $\mathrm{Nd}^{3+}$ fluorescence lifetime is mainly a function of the glass composition. To efficiently store energy in the amplifiers requires long fluorescence lifetimes. Two features of the manufacturing process can affect the lifetime- $\mathrm{Nd}^{3}+$ doping concentration and $\mathrm{H}_{2} \mathrm{O}$ absorbed in the glass. The $\mathrm{Nd}^{3+}$ content affects the lifetime at high concentrations through the wellknown concentration quenching mechanism. ${ }^{4}$ Therefore, to avoid melt-tomelt variability in fluorescence lifetime, careful control of glass volatility during the melt cycle and precise addition of $\mathrm{Nd}^{3+}$ are necessary. Absorbed $\mathrm{H}_{2} \mathrm{O}$ of only a few ppm can also affect the lifetime; therefore, very dry conditions must be maintained during melting. The hydroscopic nature of molten-phosphate laser glass makes it particularly vulnerable to $\mathrm{H}_{2} \mathrm{O}$ uptake. The $\mathrm{H}_{2} \mathrm{O}$ content of the laser glass is quantified by measuring the $-\mathrm{OH}$ absorption at $3300 \mathrm{~nm}$; Fig. 3(b) shows the results from the Beamlet melt. Although there is some variability, all slabs are quite dry having $\mathrm{H}_{2} \mathrm{O}$ absorptions between $\approx 0.2-0.6 \mathrm{~cm}^{-1}$ at $3.3 \mu \mathrm{m}$. This absorption corresporids to about 6-18 ppm of $\mathrm{H}_{2} \mathrm{O}$. Because of the good control of the $\mathrm{Nd}^{3+}$ doping concentration $\left(3.4 \pm 0.1 \times 10^{20} / \mathrm{cm}^{3}\right)$ and the $\mathrm{H}_{2} \mathrm{O}$ content, all laser glass slabs exceed the $\mathrm{Nd}^{3+}$ fluorescence lifetime specification shown in Fig. 3(c). The $\mathrm{Nd}^{3+}$ lifetime specification for Beamlet laser glass is

$\tau_{L} \geq 340-150\left(\left[\mathrm{Nd}^{3+}\right]-3.4\right)$

where $\left[\mathrm{Nd}^{3+}\right]$ is the $\mathrm{Nd}$-ion concentration in units of $10^{20} / \mathrm{cm}^{3}$ and $\tau_{\mathrm{L}}$ is the 
minimum acceptable lifetime (in microseconds). In arriving at this specification, we also included the effects of radiation trapping by the $5.0 \times 5.0 \times 0.5 \mathrm{~cm}^{3}$ standard sample size used by vendors for routine fluorescence lifetime measurements. The specification also includes the effects of concentration quenching at high $\mathrm{Nd}$ dopings, derived from work by Jancaitise 5

The Beamlet melts have very low residual $\mathrm{H}_{2} \mathrm{O}$ content so there is little effect of $-\mathrm{OH}$ quenching on the lifetime. At low levels of $\mathrm{H}_{2} \mathrm{O}$ contamination, the effect of $-\mathrm{OH}$ in reducing the lifetime can be estimated from the expression 6 $\Delta \tau=-7.62\left(\alpha_{3.3 \mu \mathrm{m}}\right)$,

where $\alpha 3.3 \mu \mathrm{m}$ is the measured $-\mathrm{OH}$ absorption at $3.3 \mu \mathrm{m}$ and $\Delta \tau$ is the lifetime reduction relative to a sample with zero residual $\mathrm{H}_{2} \mathrm{O}$. For Beamlet's laser glass, the residual $\mathrm{H}_{2} \mathrm{O}$ contributed less than a $4-\mu$ s reduction in lifetime.

We maintained good optical homogeneity during the manufacturing process with all the laser slabs meeting the homogeneity specifications. Because of the rectangular shape of the glass, there was some concern whether the homogeneity could be maintained in the corners of the slabs. All finished Beamlet laser slabs had $<0.1$ wave (at $1.054 \mu \mathrm{m}$ ) transmitted wavefront distortion across the clear aperture.

The damage threshold of the laser glass is controlled by the quality of the surface and the presence of absorbing impurities. The typical high-quality "super" polish used to finish laser glass gives a damage threshold in excess of $30 \mathrm{~J} / \mathrm{cm}^{2}$ at 3 ns $(1054 \mathrm{~nm})$ and, therefore, exceeds the requirements for Beamlet (Table 1). More important is the presence of absorbing particles within the glass, particularly $\mathrm{Pt}$ inclusions. Pt inclusions originate from the Pt containers used to melt the laser glass and can cause optical damage at fluences of $2-3 \mathrm{~J} / \mathrm{cm}^{2}$ at $3 \mathrm{~ns}$, far below the Beamlet operating fluence. In addition, damage from large inclusions can grow with 
successive shots, eventually rendering the slab useless. Using new glass-melting processes, 7,8 we were able to maintain inclusion levels well below our manufacturing goal of $<15$ in any given slab and an average for all 20 Beamlet slabs of $<3$ inclusions per slab. In fact, $50 \%$ of the laser slabs had no inclusions at all and $90 \%$ had 3 or less.

\section{KDP/KD*P}

Large plates of single-crystal KDP are used in the Beamlet Pockels cell and frequency converter. The Pockels cell and second-harmonic generation crystals are undeuterated, whereas the harmonic tripling crystal is deuterated to a level of about $80 \%$. (KD*P is the commonly used representation of the deuterated material.) The KDP and KD*P crystals are arguably the most difficult optics to manufacture and require the greatest production time. In addition, they represent a marked increase in size and quality over the crystals that were manufactured for Nova. For example, the crystal plates used on Beamlet are $37 \times 37 \mathrm{~cm}^{2}$ compared with $27 \times 27 \mathrm{~cm}^{2}$ on Nova. In addition, the Beamlet damage threshold requirement exceeds that required for Nova by about a factor of three.

The use of deuterated material for the third-harmonic crystal is driven by the need to suppress stimulated Raman scattering (SRS) at $3 \omega$. At high drive intensities (such as those used on Beamlet) the spontaneous Ramanscattered light is amplified as it traverses the crystal face. The SRS gain coefficient in KDP has been measured to be approximately $0.23 \mathrm{~cm} / \mathrm{GW}^{9,10}$ at $3 \omega$ for a Type II tripling crystal. The scattered Raman Stokes intensity $I_{S}$ grows as it travels a distance $l$ across the crystal, according to the relationship $I_{\mathrm{s}}(l)=I_{\mathrm{s}}(0) \exp \left(g I_{\mathrm{p}} l\right)$

where $I_{\mathrm{p}}$ is the pump intensity $\left(\mathrm{GW} / \mathrm{cm}^{2}\right)$ and $g$ is the gain coefficient. Because of the large aperture used on Beamlet, there is a significant gain-path 
length for the SRS light. Therefore, at high operating intensity $(>3.0$ $\mathrm{GW} / \mathrm{cm}^{2}$ ), the potential exists for the transversly propagating SRS light to reach intensities high enough to damage the $\mathrm{KD}^{*} \mathrm{P}$.

The magnitude of the SRS gain coefficient for a particular Stokes Raman band is proportional to the scattering cross section. Therefore, because the spontaneous Raman band at $915 \mathrm{~cm}^{-1}$ is the most intense in KDP, it presents the greatest threat of unacceptable SRS. In KD*P, the mode at $915 \mathrm{~cm}^{-1}$ is split into two peaks and the magnitude of each band is dependent on the deuterium concentration (Fig. 4). At high deuteration levels, the Raman scattering cross sections for the two bands are about a factor of two lower than that for the single band of the undeuterated KDP. Therefore, deuterating the KDP greatly reduces the SRS threat to the tripling crystal.

The Beamlet crystal plates were cut from large single-crystal boules of KDP and $K D^{*} P$, grown from aqueous solution by Cleveland Crystals, Inc. The KDP and $\mathrm{KD} * \mathrm{P}$ boules produced for Beamlet weigh as much as $500 \mathrm{~kg}$ and take up to 2 years to grow (Fig. 5). This is about a factor of three increase in boule volume over those grown for Nova. The crystals required for the Pockels cell and harmonic converter system are then cut from these boules in an orientation shown schematically in Fig. 6. The Pockels cell uses a crystal cut normal to the $z$-axis of the boule, whereas the frequency-conversion crystals are cut at the phase matching angles required for the specific harmonic generation scheme. Beamlet uses a Type I/II third-harmonic generation method. (The harmonic generation system is described in detail elsewhere. ${ }^{11}$ )

We chose to grow $80 \%$ deuterated material (vs $95 \%$ ) because the level of stress-induced birefringence was expected to be lower and the time to grow the boules was expected to be shorter. Deuterated water $\left(\mathrm{D}_{2} \mathrm{O}\right)$, having a deuteration level of $99.7 \%$, was obtained from the Department of Energy's national stockpile. In 
general, the growth rate for fully deuterated material is as much as 10 times slower than for undeuterated KDP.

Apart from size and deuteration level, the quality of the KDP and KD*P crystals is also of critical importance. Specifically, stresses within the crystal can lead to stress-induced index variations and birefringence that in turn can produce distortions in the optical wavefront and beam depolarization. 12-14 Wavefront distortion and depolarization degrade the performance of the laser. For example, in the case of the Pockels cell, any depolarization in the beam results in a direct transmission loss at the polarizer. Likewise, wavefront distortions can reduce the conversion efficiency of the harmonic generator, produce downstream modulation, and degrade focusability. Our operating goal for the Pockels cell was to produce $<1 \%$ depolarization loss for any given pass and to keep the transmitted wavefront distortion and wavefront gradients for the finished crystal to $<\lambda / 4$ and $\lambda / 4 \mathrm{~cm}$, respectively.

The birefringence $(\delta n)$ in a Pockels cell plate, cut normal to the $z$-axis of the crystal, is dominated by the shear strain and is given by 10 $\delta n=n^{3} p_{66} \varepsilon_{x y}$,

where $n$ is the refractive index, $\varepsilon_{x y}$ is the shear strain, and $p_{66}$ is the elasto-: optic tensor element appropriate for this geometry; $p_{66}$ has the value of 0.028 for KDP and 0.025 for $K^{*} \mathrm{DP}$. The depolarization loss $(L)$, due to this birefringence, is given by ${ }^{12}$ $L=\sin ^{2}\left[\left(\frac{\pi}{\lambda}\right) \delta n t\right]$,

where $t$ is the crystal thickness and $\lambda$ is the laser wavelength. Equation (4) is valid for the "on" and "off" states of the Pockels cell (i.e., when the voltage applied across 
the crystal is either $V \pi$ or 0 , respectively). The shear strain can be directly related to the shear stress, $\tau_{x y}$ :

$\tau_{x y}=C_{66} \varepsilon_{x y}$.

where $C_{66}$ is the elastic constant and has the value of 6.24 and $5.94 \mathrm{GPa}$ for $\mathrm{KDP}$ and $\mathrm{KD}^{* \mathrm{P}}$, respectively. To achieve a depolarization loss of $1 \%$ or less requires a shear stress $<10^{6} \mathrm{~Pa}$.

Distortions in the beam phase front transmitted through the Pockels cell $z$ plate are controlled by the residual normal strains in the crystal: 12 $\Delta n=\left(\frac{n^{3}}{2}\right)\left[\frac{1}{2}\left(p_{11}+p_{12}\right)\left(\varepsilon_{x}+\varepsilon_{y}\right)+p_{13} \varepsilon_{z}\right]$,

where $\Delta n$ is the index shift, the $p_{i j}{ }^{\prime} s$ are elasto-optic coefficients, and $\varepsilon_{x}, \varepsilon_{y}$, and $\varepsilon_{z}$ are the normal strains in the crystal. These strains can be related to residual normal stresses using the relationships developed by DeYoreo and Woods. ${ }^{14}$ The index shift produces a spatial variation in the transmitted phase given by $\phi=\left(\frac{2 \pi}{\lambda}\right) \Delta n t$.

To meet the transmitted wavefront distortion specification of $<\lambda / 8$ for the Pockels cell KDP crystal, requires a minimum residual normal stress field of $\approx 10^{5} \mathrm{~Pa}$. Also, to meet the transmitted wavefront gradient specification for the crystal requires that the stress gradient be $<10^{5} \mathrm{~Pa} / \mathrm{cm}$.

The birefringence and wavefront distortions of the crystals used on Beamlet are characterized using the method described by DeYoreo and Woods. 13 Figure 7 presents the measured depolarization loss for a $32 \times 32 \mathrm{~cm}^{2} \mathrm{KDP}$ crystal. The data show a maximum loss of $0.4 \%$ through any point in the crystal with an aperture loss averaging $0.05 \%$. The data show that the maximum residual shear stress in the crystal is $<1.5 \times 10^{5} \mathrm{~Pa}$. Similarly, interferometry measurements show phase front 
distortions from the bulk material of less than an eighth of a wave at $1054 \mathrm{~nm}$, again suggesting very low residual normal stresses in the crystal.

The KDP crystal plates are finished by diamond turning instead of polishing. In this process, a crystal blank is mounted on a carriage that translates the crystal blank parallel to the cutting plane. The cutting plane is defined by the single-point diamond tool mounted at a fixed radius in a high-speed spindle. This is commonly referred to as a fly-cutting mode of operation, and the cutting direction can be more closely aligned with a preferred axis on the crystal. By rotating the tool, rather than the crystal, the cutting rate remains the same across the whole face of the crystal. During the final finishing steps, the distance between subsequent tool cuts is usually only a few micrometers. Using this method, surface finishes of about $30 \AA$ (rms) are typical.

One recurring problem we have encountered during finishing of large KDP crystals is a small-scale waviness in the transmitted wavefront. Our initial tests on Beamlet showed this same waviness in the output $1 \omega$ near-field image [Fig. 8(a)]. This waviness originated from the diamond turned surface of the Pockels cell crystal and had a spatial scale length of about $6.3 \mathrm{~mm}$. The measured amplitude of the phase ripple suggests a surface with a $100 \AA$ peak-to-valley $(\mathrm{p}-\mathrm{V})$ periodic variation at that scale length. We investigated ways to reduce the surface waviness, because at high laser intensities the phase ripple from the diamond turning process may seed small-scale beam breakup due to self-focusing. ${ }^{15}$ The source of the waviness was traced to a problem with the carriage system that translates the crystal. Specifically, we found that the flexure coupling that connects the drive-lead screw to the carriage was not properly aligned. Therefore, the flexure coupling was unable to adequately remove the natural once-per-revolution "wobble" motion of the lead screw. In this condition, the increased transmission of the lead-screw wobble into the carriage caused the crystal blank to move excessively in and out of the cutting plane in a 
sinusoidal fashion. After adjusting the flexure coupling, we found that the surface waviness was greatly reduced. Transmitted wavefront measurements on crystals finished before and after this repair showed that for scale lengths of $\approx 6 \mathrm{~mm}$, the $p-V$ surface waviness on the crystals was reduced from $\approx 80 \AA$ to $\approx 25 \AA$. Figure 8 compares the near-field image of the Beamlet output beam vefore and after this corrective measure. Note that the circular arcs due to the spatial ripple are completely absent in the "after" near-field image/ $[7 y f(b)]$

The damage threshold of some optical materials can be improved by "laser conditioning." $\mathrm{KDP}$ and $\mathrm{KD} * \mathrm{P}$ are two such materials. During the process of laser conditioning, the optical material is exposed to a series of laser shots with monotonically increasing fluence. The wavelength of the conditioning laser shots is the same as the wavelength at which the optic is intended to be used. At the end of this sequence of exposures, the optical damage threshold is typically increased by a factor of two or more over the unconditioned (i.e., single-shot) threshold. As a general rule of thumb, at least five shots are needed to condition the optic to $\approx 85 \%$ of the maximum conditioned threshold. Furthermore, the first shot in the conditioning sequence should be at a fluence of about one-half the unconditioned damage threshold.

Table 2 summarizes the unconditioned and conditioned damage thresholds of $K D P$ and $K D * P$ at $1 \omega$ and $3 \omega$, respectively.

\section{Dielectric Coatings}

Two main types of optical coatings are used on Beamlet: (1) multilayer $\mathrm{HfO}_{2} / \mathrm{SiO}_{2}$ high-reflectivity ( $\mathrm{HR}$ ) and polarizer coatings and (2) single-layer $\mathrm{SiO}_{2}$ solgel antireflection (AR) coatings. Figure 9 shows the Beamlet polarizer and two of the mirrors. The sol-gel AR coating design, coating process, optical performance, and damage threshold have been well documented $16-18$ and will not be discussed here. 
We note only that these coatings are routinely applied to all Beamlet and Nova transmissive optics (large and small) and have excellent transmission (>99.5\% per surface) and high damage thresholds at $1 \omega$ and $3 \omega$ (Table 1 ).

Beamlet uses $\mathrm{HfO}_{2} / \mathrm{SiO}_{2}$ multilayer coatings because of their demonstrated damage threshold improvement with laser conditioning, 19,20 good optical properties, and relative ease in application over large apertures by electron beam (ebeam) evaporation. 21 All the multilayer coatings on large-aperture Beamlet optics were applied by conventional e-beam processing.

There are three reasons the polarizer is the most difficult optical coating to make: (1) The size of the polarizer is $75 \times 39 \times 9 \mathrm{~cm}^{3}$ and is more than twice the size of anything previously manufactured. (2) The damage threshold of the polarizer required for Beamlet represents a three-fold improvement over those used on Nova. (3) The coating layers need to be uniformly and precisely deposited over the entire substrate surface.

The polarizer coating was deposited on a BK-7 silicate glass substrate. BK-7 is significantly lower in cost than $\mathrm{SiO}_{2}$, although it has the disadvantage of having a low bulk damage threshold due to $\mathrm{Pt}$ inclusions in the glass. However, because the polarizers used on Beamlet are used in reflection at high intensity, the BK-7 substrate is never exposed to damaging fluences.

- Table 3 summarizes the transmission properties of the four polarizers manufactured for Beamlet by Spectra-Physics. The optimum-use angle is between 54.5 and $56^{\circ}$ and the polarizer can be "tuned" to the maximum extinction ratio by rotating the optical mount that holds the polarizer over the specified use range. We manufactured four polarizers: two are used on the system and two are spares. The polarizers were prepared in two separate coating production runs (with two polarizers in each run); the reproducibility between the two runs was quite good. Three of the polarizers had extinction coefficients $>390$, supporting the excellent 
control of the deposition process. The reflected wavefront distortion is between $\approx 0.25$ and 0.4 waves and is largely due to spherical aberration that can be easily corrected by other optical elements in the system.

$\mathrm{HfO}_{2} / \mathrm{SiO}_{2}$ e-beam coatings can be laser conditioned to improve their damage threshold. (The conditioning process is similar to that described previously for KDP.) The conditioned damage thresholds of the polarizers all exceeded the Beamlet safe operating limit of $8 \mathrm{~J} / \mathrm{cm}^{2}$ at $3 \mathrm{~ns}$ (Table 3). The polarizers were conditioned offline using the output from a pulsed Nd:YAG laser, operating at $10 \mathrm{~Hz}$, to scan the full aperture of the optic in incremental fluence steps. 22 The conditioning effect has been associated with the gentle removal of nodular-shaped defects, which are known to limit the damage threshold of these multilayer coatings. ${ }^{23}$ Based on measurements, the damage threshold of the polarizers scales with the pulse length as $\tau^{0.35}$.

The $\mathrm{HfO}_{2} / \mathrm{SiO}_{2}$ thin-film mirrors on Beamlet all had measured damage thresholds exceeding $25 \mathrm{~J} / \mathrm{cm}^{2}$ and reflectivities $>99 \%$. Damage thresholds of mirror coatings are typically higher than those of similar polarizer coatings.

\section{Lenses and Diagnostic Beam Splitters}

The lenses and diagnostic beam splitters used on Beamlet were all: fabricated from fused silica, manufactured by Corning. The fused silica is prepared by flamehydrolysis of $\mathrm{SiCl}_{4}$ and is inclusion free. As a consequence, the damage threshold is limited by the surface finish and AR coating on the optic, not the bulk material. Extensive front-surface damage measurements at 1.0 and $0.35 \mu \mathrm{m}$ and over a range of pulse lengths give a simple empirical relationship governing the safe operating limit for bare surface fused silica of $\mathrm{D}=22 \mathrm{tp}_{\mathrm{p}}^{0.4}$ (at $\left.1.0 \mu \mathrm{m}\right)$ and 
$\mathrm{D}=9.2 \mathrm{tp}^{0.5}$ (at $0.35 \mu \mathrm{m}$ ),

where $t_{p}$ is the pulse length (ns) and $D$ is the damage threshold $\left(J / \mathrm{cm}^{2}\right)$. When a solgel AR coating is applied to the fused silica surface, the safe operating limit is

slightly higher than that measured for the bare surface material, specifically: 24

$\mathrm{D}=24.6 \mathrm{tp}^{0.4} \quad$ (at $\left.1.0 \mu \mathrm{m}\right)$

and

$\mathrm{D}=13.7 \mathrm{tp}^{0.5} \quad$ (at $\left.0.35 \mu \mathrm{m}\right)$.

\section{Summary}

Nearly all of the large optics used on Beamlet represent a dramatic increase in size and optical quality over those used on previous ICF lasers. Specifically the laser slabs, KDP/KD*P crystals, and polarizers are more than a factor of two larger than those used on Nova. In addition, the damage thresholds and quality of the Beamlet optical materials are also improved by two- to three-fold over those used on Nova. The sizes and quality of optics used in Beamlet closely match those expected to be used in the proposed NIF.

\section{Acknowledgment}

The authors gratefully acknowledge Cleveland Crystals, Inc., Corning, Eastman Kodak Company, Schoțt Glass Technologies Inc., Spectra-Physiçs, Tinsley Laboratories, Inc., and Zygo Corporation for their outstanding efforts in providing high-quality optical materials or optical finishing for Beamlet.25-31 We also acknowledge the support of Kevin Kyle for providing the data on deuteration effects on the Raman spectrum of KDP and Frank Rainer and Frank DeMarco for providing damage threshold measurements. 


\section{Notes and References}

1. J. E. Murray, H. T. Powell, G .F. Ross, and J. D. Wintemute, Technical Digest, Annual Meeting, Opt Soc of Am, Washington, DC, TUU9 (1988).

2. J. H. Campbell, G. Edwards, F. Frick, D. Gemmell, et al., Laser-Induced Damage in Optical Materials: 1986, (NIST, Special Publication, Boulder, CO, 1987; NIST 752) p. 19.

3. S. E. Stokowski and D. Krashkevich, Mat. Res. Soc. Symposium Proc. 61, 273 (1986).

4. H. G. Danielmeyer, M. Blatte, and P. Balmer, Appl. Phys. 1, 269-274 (1973).

5. K. Jancaitis, "Updated Model for the Decay of the Inversion in LG-750 ND:Glass," LLNL internal memo, LS\&T, 91-35 (Apr 1990).

6. J. A. Caird, N. D. Nielsen, and J. E. Murray, "Water Contamination and Fluorescence Lifetime in Nova Laser Glass," LLNL internal memo, ADG-88-138 (Dec 7, 1988).

7. J. H. Campbell, E. P. Wallerstein, J. S. Hayden, D. L. Sapak, et al., Glastech. Ber. Glass Sci. Technol. 68(1), 1-11 (1995).

8. J. H. Campbell, E. P. Wallerstein, H. Toratani, H. Meisgner, et al., Glastech. Ber. Glass Sci. Technol. 68(2), 1-11 (1995).

9. R. A. Sacks, C. E. Barker, and R. B. Ehrlich, ICF Quarterly Report 2(4), 179-188, Lawrence Livermore National Laboratory, Livermore, CA, UCRL-LR-105821-924 (1992).

10. W. Lee Smith, F. P. Milanovich, and M. A. Henesian, LLNL memorandum UVM 83-02 (Feb. 25, 1983).

11. C. E. Barker, D. Milam, and R. Boyd, ICF Quarterly Report 3(2), 55-62, Lawrence Livermore National Laboratory, Livermore, CA, UCRL-LR-105821-93-2 (1993). 
12. J. J. DeYoreo, J. Britten, R. Vital, K. Montgomery, et al., ICF Quarterly Report 3(3), 103-111, Lawrence Livermore National Laboratory, Livermore, CA, UCRLLR-105821-93-3 (1993).

13. J. J. DeYoreo and B. W. Woods, Inorganic Crystals for Optics, Electro-Optics and Frequency Conversion, (SPIE-International Society for Optical Engineering, Bellingham, WA, 1991; Proc. SPIE 1561) p. 50.

14. J. J. DeYoreo and B. W. Woods, J. Appl. Phys. 73, 1 (1993).

15. J. T. Hunt, J. A. Glaze, W. W. Simmons, and P. Renard, Appl. Opt. 17, 2053-2057 (1978).

16. I. M. Thomas, Appl. Opt. 25, 1481 (1986).

17. I. M. Thomas, J. G. Wilder, W. H. Lowdermilk, and M. C. Staggs, Laser Induced Damage in Optical Materials: 1984, (NBS Special Publication, 1986; NBS 727) p. 205-210.

18. M. C. Staggs, D. Milam, I. M. Thomas, and J. G. Wilder, Laser Induced Damage in Optical Materials: 1985, (NBS Special Publication, 1988; NBS 746) p. 404-411.

19. M. R. Kozlowski, I. M. Thomas, J. H. Campbell, and F. Rainer, Thin Films for Optical Systems, (SPIE, Bellingham, WA, 1992; Proc. SPIE 1782) p. 105-121.

20. M. R. Kozlowski, C. R. Wolfe, M. Staggs, and J. H. Campbell, Laser Induced Damage in Optical Materials: 1989, H. Bennett, L. Chase, A. Guenther, B. Newnam, and M. J. Soileau, Eds., (NIST, Special Publication, 1990; NIST 801) p. 375.

21. M. R. Kozlowski, R. Chow, and I. M. Thomas, Handbook of Laser Science and Technology, M. Weber, Ed., (CRC Press, 1995) pp. 767-812.

22. L. Sheehan, M. Kozlowski, F. Rainer, and M. C. Staggs, Laser Induced Damage in Optical Materials: 1993, (SPIE, Bellingham, WA, 1994; Proc. SPIE 2114) pp. $559-568$. 
23. M. R. Kozlowski, R. J. Tench, R. Chow, and L. M. Sheehan, Optical Interference Coatings, (SPIE, Bellingham, WA, 1994; Proc. SPIE 2253) pp. 743-750.

24. J. H. Campbell and F. Rainer, Lawrence Livermore National Laboratory, Livermore, CA, Report, UCRL-JC-109255, SPIE ‘92 Conference Proceedings, San Diego, CA, July 1992).

25. Cleveland Crystals, Inc., 676 Alpha Dr., Highland Heights, OH 44143.

26. Corning Glass Works, MP-21-04-2, Corning, NY 14831.

27. Eastman Kodak Company, Dept. 177, Bldg. 601, Rochester, NY 14650-0803.

28. Schott Glass Technologies Inc., 400 York Ave., Duryea, PA 18642.

29. Spectra-Physics Components \& Accessories, 1330 West Middlefield Rd., Mountain View, CA 94039-0517.

30. Tinsley Laboratories, Inc., 3900 Lakeside Dr., Richmond, CA 94806.

31. Zygo Corporation, Laurel Brook Rd., Middlefield, CT, 06455-0448. 
Figure captions:

Figure 1. Comparison of the peak laser fluence during the final pass through the laser system with the "safe operating limits" of the material. The data are for a nominal square output pulse of 3 ns.

Figure 2. Beamlet's $78.8 \times 44.8 \times 4 \mathrm{~cm}^{3}$ laser slab containing $3.4 \times 10^{20}$ $\mathrm{Nd}^{3+} / \mathrm{cm}^{3}$; the edges of the laser slab are clad with a $\mathrm{Cu}$-doped phosphate glass designed to absorb ASE at $1054 \mathrm{~nm}$.

Figure 3. Summary of three key properties of the laser slabs produced for Beamlet compared with the design specifications: (a) absorption loss at 1054 $\mathrm{nm}$, (b) $-\mathrm{OH}$ absorption at $3000 \mathrm{~nm}$, and (c) fluorescence lifetime. The lifetime measurements were performed on samples $5 \times 5 \times 0.5 \mathrm{~cm}^{3}$.

Figure 4. Measured spontaneous Raman scattering intensity profile for the $915 \mathrm{~cm}^{-1}$ mode at different deuteration levels.

Figure 5. Photograph of a large KDP single crystal grown for Beamlet (note the meter stick shown for scale). The Beamlet crystals each weigh about $500 \mathrm{~kg}$ and are the largest ever produced. The smaller crystal on the right is the size grown for Nova.

Figure 6. Schematic diagram showing the orientation in which the crystal plates used on Beamlet are cut from large KDP and KD*P single-crystal boules. (a) Type I doubler, (b) Type II tripler, and (c) Pockels cell z-plate. In general, several crystals of a given type can be cut from one boule. 
Figure 7. Strain-induced depolarization loss in z-cut (a) KD*P and (b) KDP plates $\left(32 \times 32 \times 1 \mathrm{~cm}^{3}\right)$.

Figure 8. Near-field images of the $1 \omega$ output on Beamlet showing (a) the intensity modulation caused by diamond turning "ripples" on the Pockels cell KDP crystal, and (b) elimination of the ripples after the diamond turning machine is properly adjusted.

Figure 9. Photograph of the large-aperture $\mathrm{HfO}_{2} / \mathrm{SiO}_{2}$ thin-film polarizer used with the PEPCs on Beamlet to switch the beam out of the multipass cavity. The polarizer is used in a transmissive mode at low fluence ( $\mathrm{p}$ polarized incident light) during the first and second pass. On the final pass, the light is s-polarized and reflected off the polarizer coating and out of the cavity. The peak fluence is about $11 \mathrm{~J} / \mathrm{cm}^{2}$ at $3 \mathrm{~ns}$ (1054 nm). 
Table 1. Beamlet's damage threshold requirements and measured values at 3 ns for various optical materials.

\begin{tabular}{|c|c|c|c|c|}
\hline & Optics & $\begin{array}{l}\text { Measured } \\
\text { damage threshold } \\
\left(\mathrm{J} / \mathrm{cm}^{2}\right)\end{array}$ & $\begin{array}{l}\text { Safe } \\
\text { operating } \\
\text { limit }\left(\mathrm{J} / \mathrm{cm}^{2}\right)\end{array}$ & $\begin{array}{l}\text { Beamlet peak } \\
\text { fluence } \\
\left(\mathrm{J} / \mathrm{cm}^{2}\right)\end{array}$ \\
\hline \multirow[t]{7}{*}{$1 \omega$} & Laser glass & 34 & 28 & 20 \\
\hline & $\mathrm{HfO}_{2} / \mathrm{SiO}_{2} \mathrm{HR}$ & 26 & 18 & 8 \\
\hline & $\mathrm{HfO}_{2} / \mathrm{SiO}_{2}$ & 22 & 15 & 8 \\
\hline & polarizer & & & \\
\hline & $\mathrm{SiO}_{2}$ sol-gel AR & 34 & 29 & 21 \\
\hline & KDP doubler & 43 & 30 & 20 \\
\hline & KDP (Pockels cell) & 43 & 30 & 8 \\
\hline \multirow[t]{2}{*}{$3 \omega$} & $\mathrm{KD} * \mathrm{P}$ tripler & 20 & 14 & 11 \\
\hline & $\mathrm{SiO}_{2}$ sol-gel $\mathrm{AR}$ & 17 & 14 & 11 \\
\hline
\end{tabular}

$\mathrm{HR}=$ high reflectivity; $\mathrm{AR}=$ antireflection 
Table 2. Summary of damage threshold for KDP and KD*P crystal plates used on Beamlet.

\begin{tabular}{|c|c|c|c|}
\hline Optic & Material & $\begin{array}{l}\text { Wavelength } \\
\text { (nm) }\end{array}$ & $\begin{array}{l}\text { Damage threshold at } 3 \mathrm{~ns} \\
\left(\mathrm{~J} / \mathrm{cm}^{2}\right) \\
\text { unconditioned conditioned }\end{array}$ \\
\hline $\begin{array}{l}\text { Pockels cell } z \text { - } \\
\text { plate }\end{array}$ & KDP & 1054 & 34 \\
\hline Type I doubler & KDP & 1054 & 34 \\
\hline \multirow[t]{2}{*}{ Type II tripler } & $K D^{*} \mathrm{P}$ & 1054 & 25 \\
\hline & & 351 & 10 \\
\hline
\end{tabular}


Table 3. Summary of transmission, extinction ratio, and reflected wavefront distortion for the four $79(x) 3999$ $\mathrm{cm}^{3} \mathrm{HfO}_{2} / \mathrm{SiO}_{2}$ thin film polarizers manufactured for Beamlet (measured in dry $\mathrm{N}_{2}$ ).

\begin{tabular}{|c|c|c|c|c|c|c|c|}
\hline \multirow[t]{2}{*}{$\begin{array}{l}\text { Polarizer } \\
\text { designation }\end{array}$} & \multirow[t]{2}{*}{$\begin{array}{l}\text { Optimu } \\
\text { angle } \\
\text { ase }\end{array}$} & \multicolumn{2}{|c|}{$\begin{array}{l}\text { Transmission (\%) } \\
\text { p-polarized / s-) } \\
\text { polarized }\end{array}$} & \multirow[t]{2}{*}{$\begin{array}{l}\text { Extinction } \\
\text { ratio } \\
\mathrm{T}_{\mathrm{p}} / \mathrm{T}_{\mathbf{S}}\end{array}$} & \multirow[t]{2}{*}{$\begin{array}{l}\text { Reflected wavefront } \\
\text { distortion (in waves } 1.05 \\
\mu \mathrm{m} \text { ) }\end{array}$} & \multirow{2}{*}{\multicolumn{2}{|c|}{$\begin{array}{l}\text { Conditioned Damage } \\
\text { Threshold at } 1.054 \mu \mathrm{m} \text { and } 3 \\
\text { ns }\left(\mathrm{J} / \mathrm{cm}^{2}\right) \mathrm{a} \\
\text { (D-polarized }\end{array}$}} \\
\hline & & $T_{p}$ & $1 / \mathrm{s}$ & & & & \\
\hline 1 & $55.5^{\circ}$ & 98.2 & 0.60 & 163 & 0.4 & 18 & 23 \\
\hline 2 & $54.5^{\circ}$ & 98.1 & 0.10 & 981 & 0.25 & 20 & 26 \\
\hline 3 & $56^{\circ}$ & 98.0 & 0.25 & 392 & 0.28 & 13 & 18 \\
\hline 4 & $54.5^{\circ}$ & 98.2 & 0.14 & 701 & 0.38 & 20 & 35 \\
\hline
\end{tabular}

aDamage measurements on witness samples from the production run. 


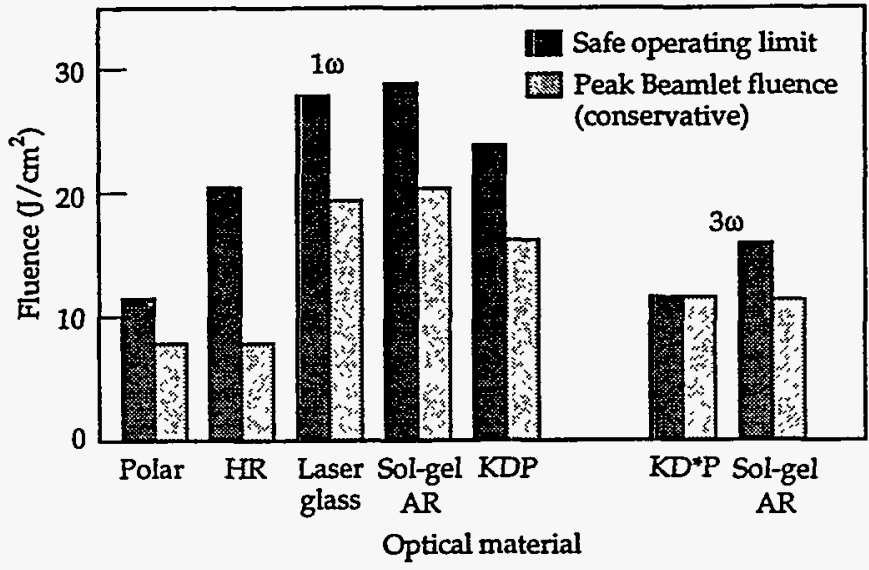

70-50-0693-2242pb01

ICF Quarterly 95/1

Campbell/01

LWH/2/7/95 


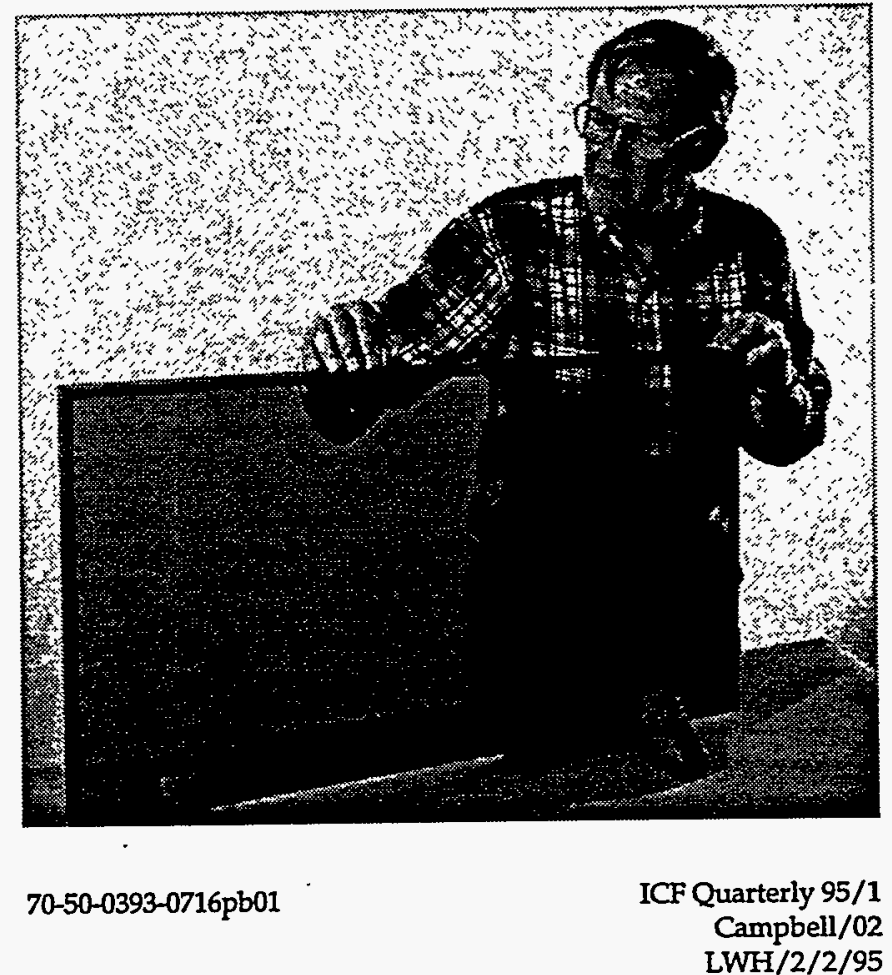


(a) Absorption loss at $1054 \mathrm{~nm}$
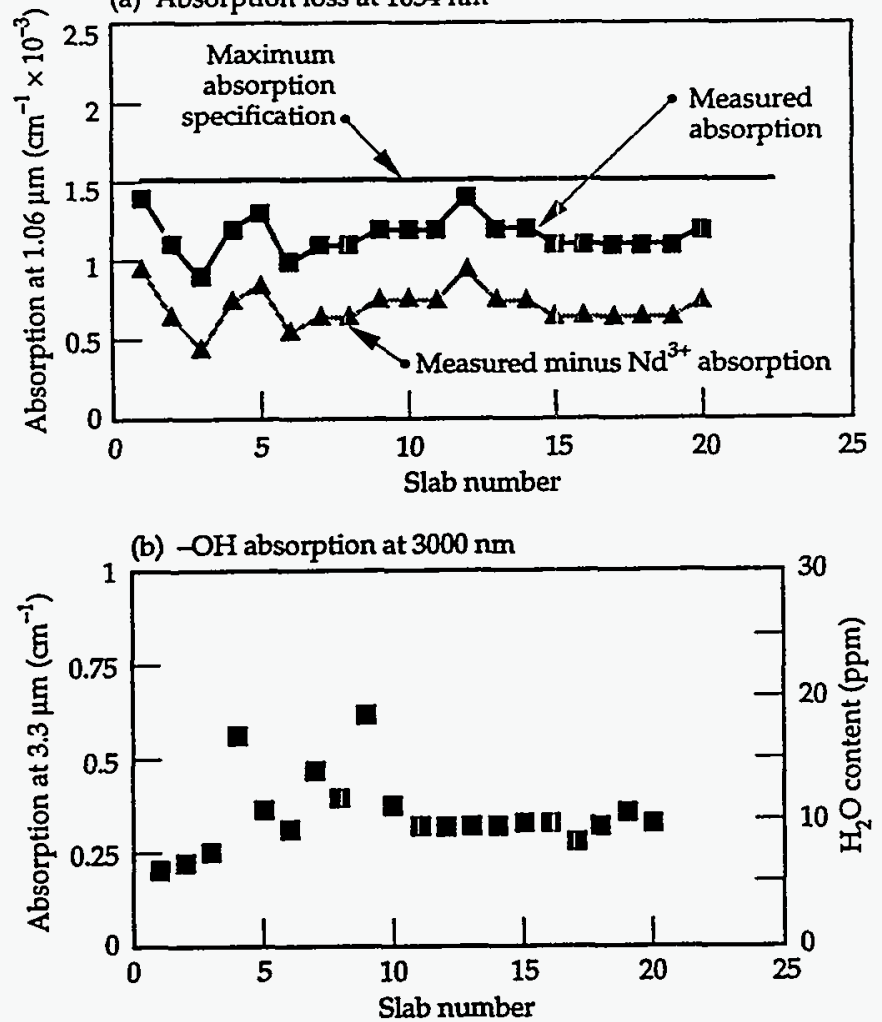

(c) Fluorescence lifetime

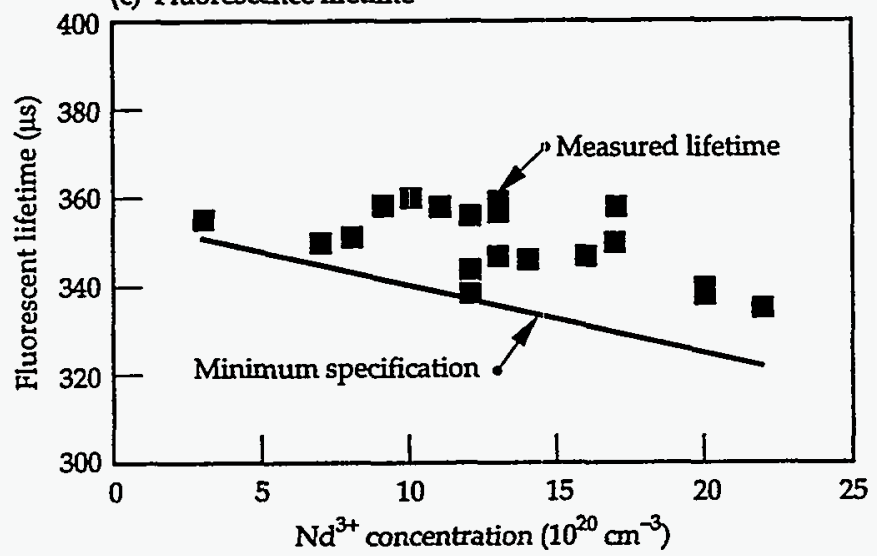

70-50-0295-0397pb01

ICF Quarterly 95/1

Campbell/03

LWH/2/7/95

cx/lwh/2/23/95 


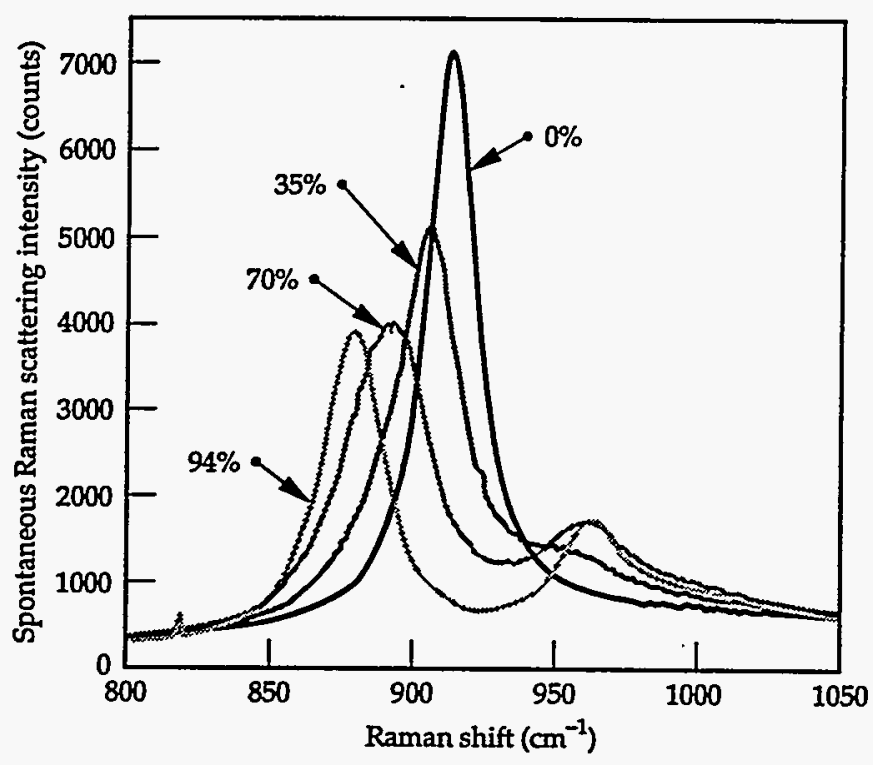

70-35-0195-0316pb01

ICF Quarterly 95/1

Campbell/04

LWH/2/3/95 


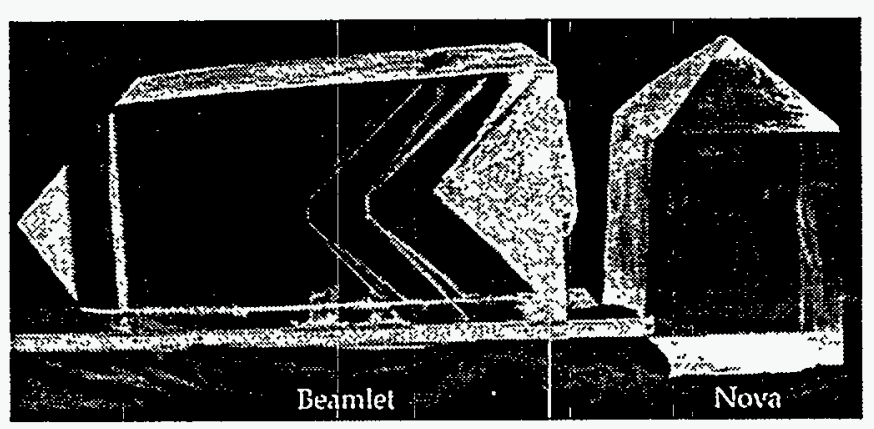

'70-39-1093-3487pb01

ICF Quarterly 95/1

Campbell/05

LWH/2/2/95 
(a) Type I doubler

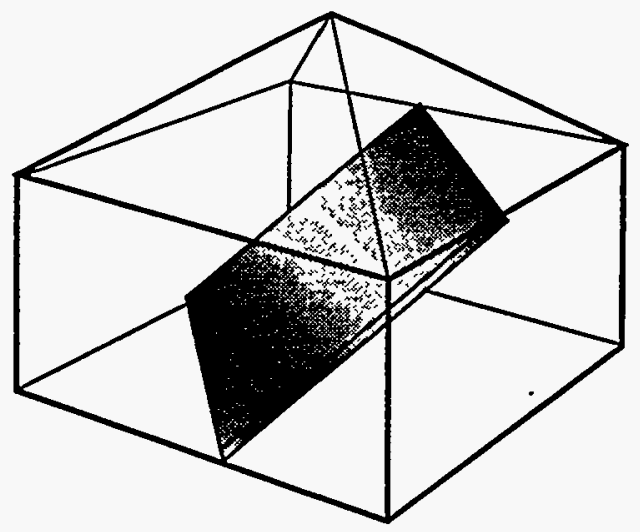

70-35-0195-0317pb01 (b) Type II tripler

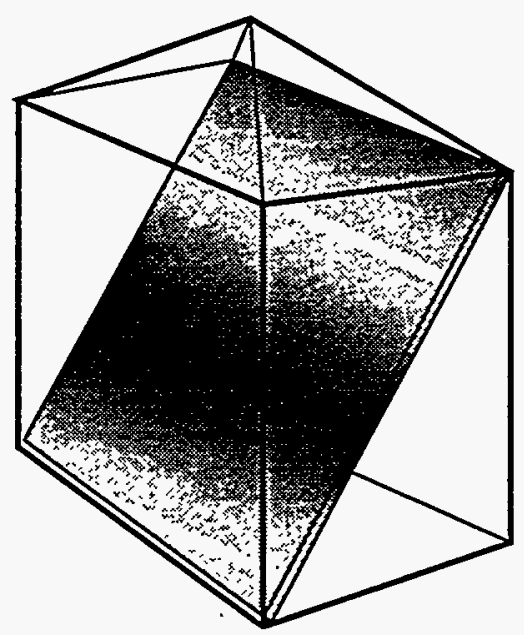

(c) Pockels cell z-plate

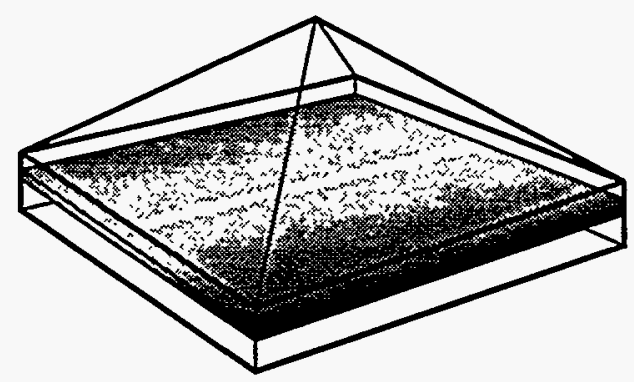

ICF Quarterly 95/1 Campbell/06 LWH/2/3/95 
ธ6/E乙/乙/ЧMI/XO

S6/‡I/Z/HMI

$\angle 0 /$ IIJqdures

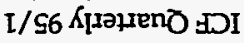

Z0qdZ86ع- $6 Z I-0 \varsigma-0 L$
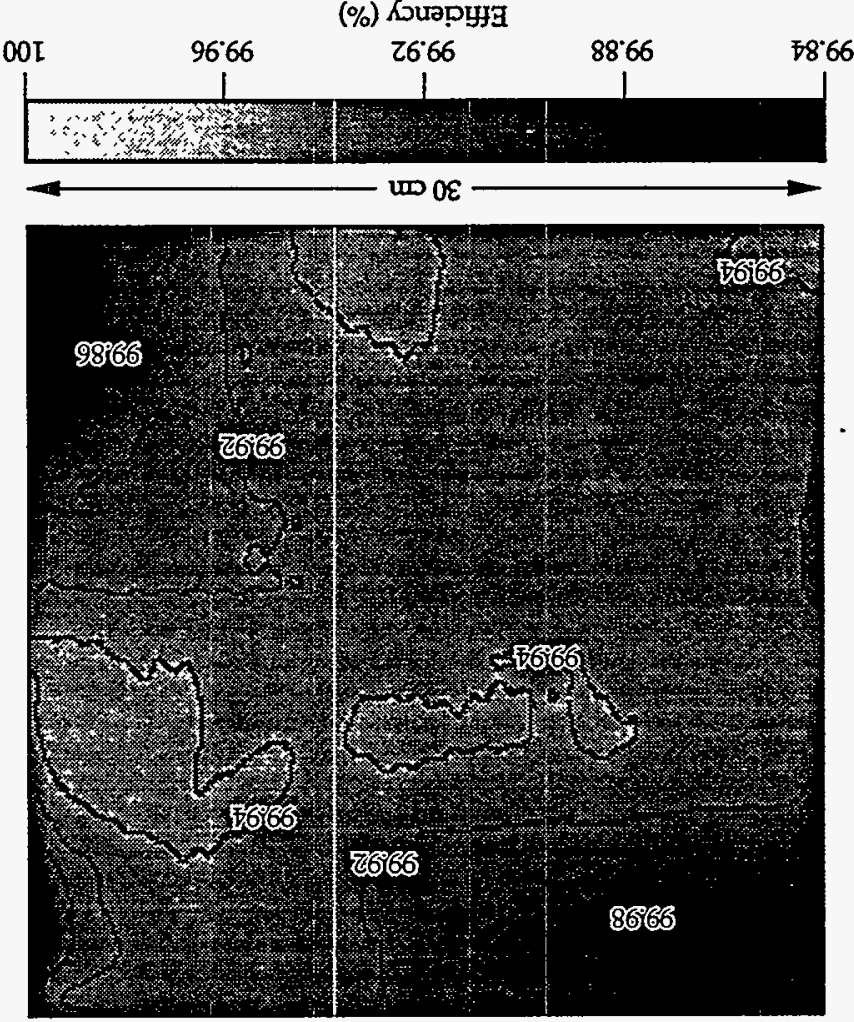

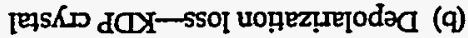
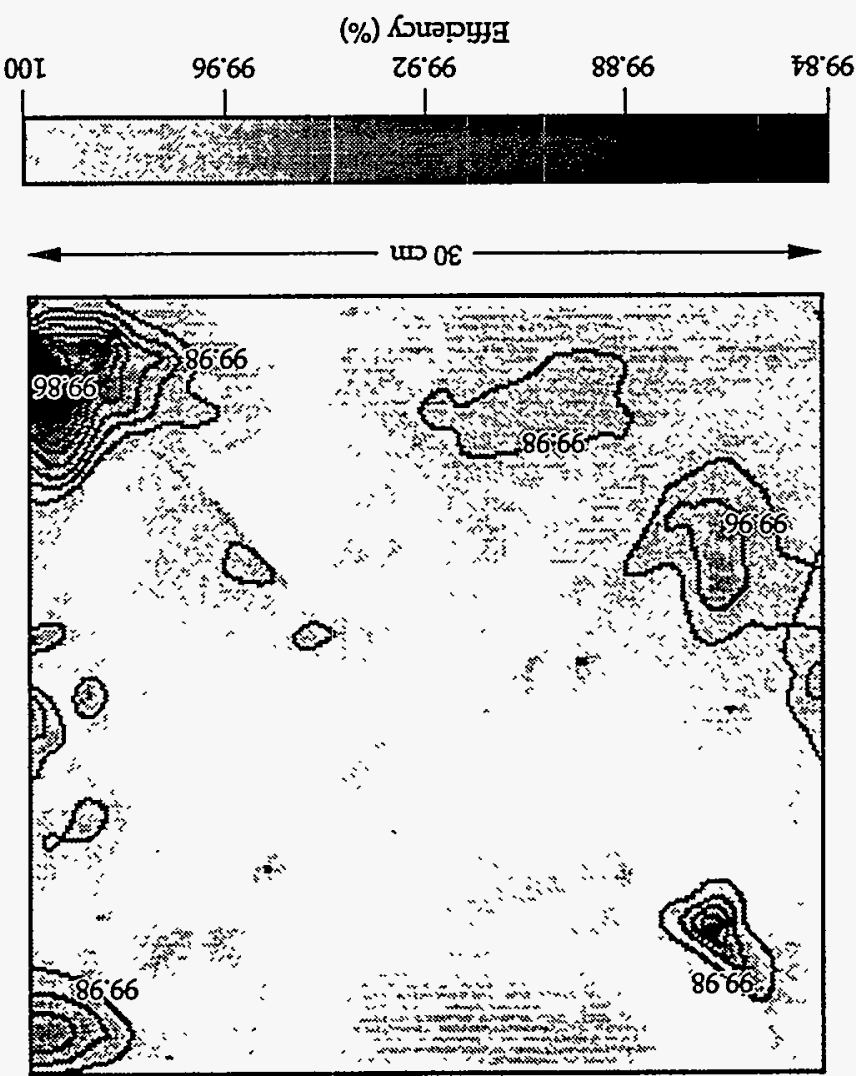

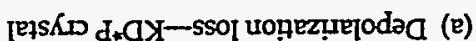


G6/EZ/Z/HMT

80/IIrqdures

I/S6 א[xa\}reno DDI

I0qd $\varepsilon 6 \subseteq 0-\subseteq 620-0 \varsigma-0 \angle$
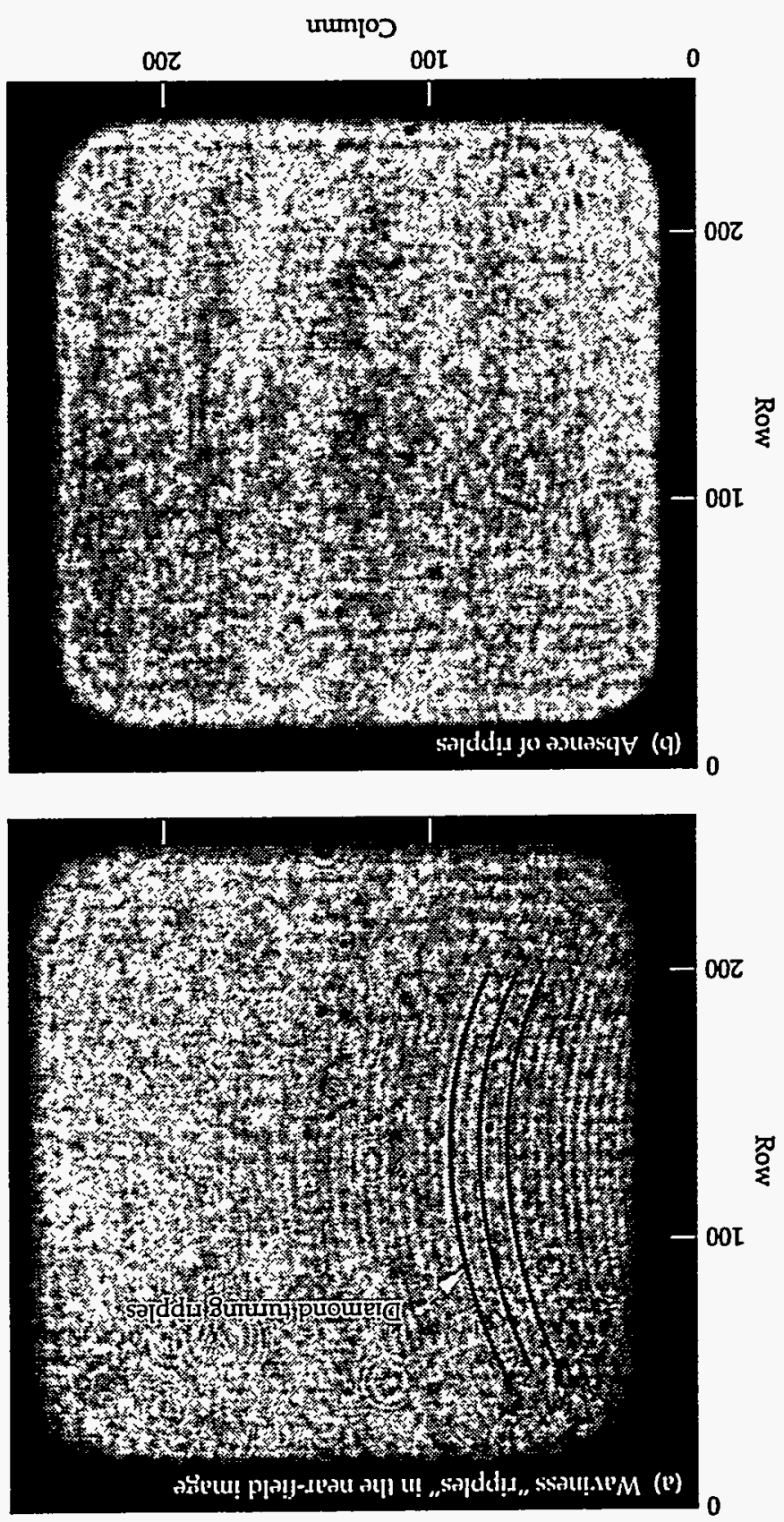


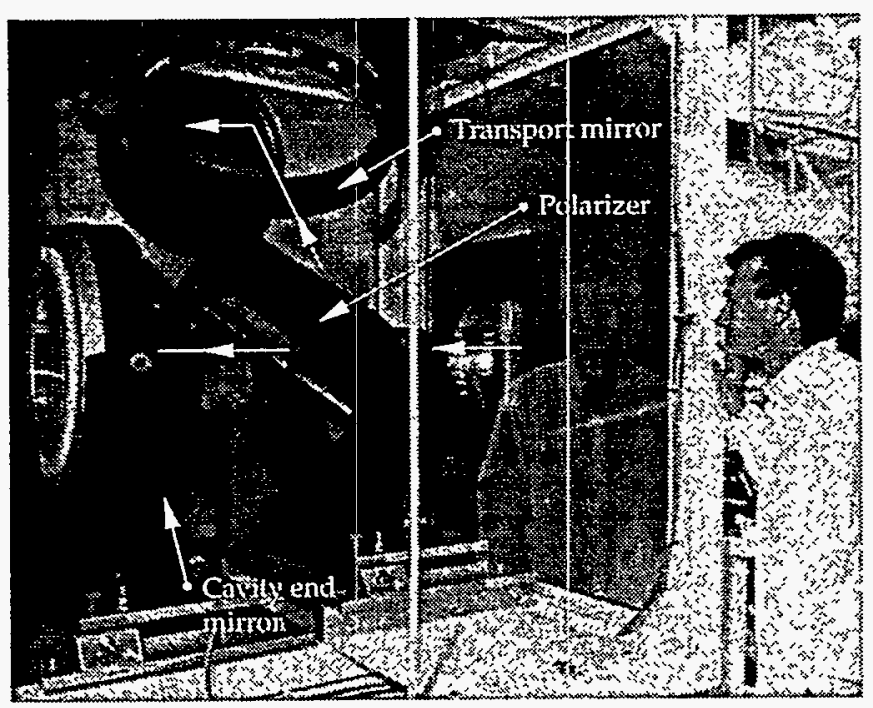

70-50-0594-2486pb01

ICF Quarterly 95/1 Campbell/09 LWH/2/2/95 